\title{
Examination of the material removal mechanisms during the lapping process of advanced ceramic rolling elements
}

\author{
J. Kang ${ }^{\mathrm{a}}$, M. Hadfield ${ }^{\mathrm{b}}$ \\ ${ }^{a}$ Department of Design and Systems Engineering, Brunel University, Runnymede Campus, \\ Egham, Surrey TW20 0JZ, UK \\ ${ }^{b}$ School of Design, Engineering \& Computing, Bournemouth University, Bournemouth BH1 3LT, UK
}

\begin{abstract}
Two types of HIPed $\mathrm{Si}_{3} \mathrm{~N}_{4}$ bearing ball blanks with different surface hardness and fracture toughness were lapped under various loads, speeds, and lubricants using a novel eccentric lapping machine. The lapped surfaces were examined by optical microscope and SEM. The experimental results show that the material removal rate for type one ball blanks were $3 \sim 4$ fold of type two in most cases. Different lapping fluids affected the material removal rate at lower lapping loads, but they had much less influence on the material removal rate at higher lapping loads. The SEM micrographs reveal that the grain pull-out prevailed on the lapped surface of type one ball blanks, and the surface of type two featured bulk material removal by microcracking. Under extreme high lapping load, surface cracks and damages were found and SEM with EDX disclosed steel from the lapping plate had transferred to the ceramic ball surface. The preliminary conclusion is that the material removal mechanism during the lapping process of silicon nitride balls using this eccentric lapping machine is mainly mechanical abrasive wear. Law and Wilshaw's indentation model on brittle materials is used to explain the difference in material removal rate for the two types of ball blanks.
\end{abstract}

Keywords: Abrasion, Ceramics, Surface, Lapping

\footnotetext{
* Corresponding author. Tel. +44 (0)1202 702751 Fax. +44 (0)1202 702758

E-mail: mhadfield@bournemouth.ac.uk
} 


\section{Introduction}

Silicon nitride is a ceramic material with the optimum combination of properties - low density, high elastic modulus, corrosion resistance and temperature resistance - to be used for rolling elements in hybrid precision ball bearings. Unfortunately, the high manufacturing cost, especially in the finishing process, hinders their widespread application. In order to accelerate the finishing process of silicon nitride rolling elements, the material removal mechanisms must be fully understood.

Some research on the material removal mechanisms in the finishing process of ceramics have been conducted. Chandrasekar and Farris [1] concluded that the material removal processes in grinding, lapping and polishing of ceramics can be considered as two-body or three-body wear. The mechanical action of the abrasive can be thought of as the repeated application of relatively sharp sliding indenters to the surface. Under these conditions, a small number of mechanisms dominate the material removal process. These are brittle fracture due to crack systems oriented both parallel (lateral) and perpendicular (radial/median) to the surface, ductile cutting with the formation of thin ribbon-like chips and chemically assisted wear in the presence of a reactant that is enhanced by the mechanical action (tribochemical reaction). The relative role of each of these mechanisms in a particular finishing process can be related to the load applied to an abrasive particle, the sliding speed of the particle, and the presence of a chemical reactant. These wear mechanisms also cause damage to the near surface in the form of microcracking, residual stress, plastic deformation and surface roughness which together determine the strength and performance of the finished component.

A model was built by Buijs and Korpelvanhouten [2,3] for three-body abrasion of brittle materials which is based on material removal by rolling abrasive particles. The particles indent the workpiece surface and remove material by lateral cracking. Median cracking introduces subsurface damage. The model leads to expressions for removal (or wear) rate, surface roughness, subsurface damage and load per particle as a function of particle shape, particle size, material parameters of workpiece and lapping plate, applied pressure and relative velocity between plate and workpiece. The model was found to give a good description of the experimental results, allowing among other things the calculation of removal rate, surface roughness or damage penetration from the measurement of any one of these parameters. An indentation model for the lapping of ceramics was also proposed by Ahn and Park [4] to predict 
surface roughness $R_{a}$ and $R_{t}$. Bulsara et al. [5] developed a model to determine the number and sizes of abrasive particles involved in material removal by polishing, and the forces acting on these particles. Gardos and Hardisty [6] first reported that the abrasive or polishing wear rate of silicon nitride balls is dependant on fracture toughness $\mathrm{K}_{\mathrm{IC}}$ and hardness $\mathrm{H}_{\mathrm{V}}$. Later Dill, Gardos and Hardisty [7] reported that the grinding wear of individual silicon nitride balls increased at different rates as a function of load and no simple relationship between hardness, fracture toughness and grinding rate could be found.

Chromium oxide $\left(\mathrm{Cr}_{2} \mathrm{O}_{3}\right)$ was found to be an excellent abrasive for polishing silicon nitride and chemical analysis showed that $\mathrm{Cr}_{2} \mathrm{O}_{3}$ participated in the chemomechanical polishing of silicon nitride to form chromium nitride and chromium silicate [8].

Water can accelerate the abrasive ratio by tribochemical reaction with silicon nitride. M. Woydt and U. Effner [9] [10] studied the wear of ceramics under water lubrication. The materials $\mathrm{SiC}, \mathrm{ZrO}_{2}$ and $\mathrm{Si}_{3} \mathrm{~N}_{4}$-TiN are not applicable since water accelerates the pitting formation. Only HIP-Si $\mathrm{N}_{4}$ can be used as it demonstrates a wear rate a hundred times higher than paraffinic oil. This was further confirmed by Hah \& Fischer [11], Jisheng \& Stolarski [12]

The material removal mechanisms during the lapping process of advanced ceramic rolling elements (balls) are very complicated. Lapping can be considered as a three-body wear, with abrasive particles acting like indenters sliding and rolling between the lapping plate and the workpiece. The lapping fluid serves as lubricant and may also have tribochemical reactions with the workpiece. During lapping, as the stock is removed from the workpiece, the abrasive particles are also worn and broken down to a smaller size, and the lapping plates are worn as well. These worn debris are constantly added to the lapping fluid thus changing the viscosity of the fluid, and erosive wear may also occur. Abrasive particles can be embedded in the lapping plate and it then will act like a grinding wheel. In the lapping process of ceramic balls, the balls are rolling and spinning between the two lapping plates. Abrasive particles are constantly brought into, and exited from contact between balls and plates. This unique ball-lapping kinematics makes theoretical analysis more difficult than lapping on a flat surface.

A novel eccentric lapping machine was built to study the finishing process of advanced ceramic rolling elements [15]. The finishing process of advanced ceramic rolling elements constitutes two steps: lapping and polishing. In the first step - lapping, maximum material removal rate is the goal while achieving fairly good ball roundness and maintaining no consequent ball surface and subsurface damage. The second step in the finishing process is polishing, in which the ball surface roughness, 
roundness, dimensional and geometric accuracy are achieved. During polishing, the average load and speed are much lower than lapping, and the diamond particle sizes are $1 \mu \mathrm{m}$ to $1 / 4 \mu \mathrm{m}$. The polished ball surface roughness value $\mathrm{Ra}$ is $0.003 \mu \mathrm{m}$ which is above grade 3 precision bearing ball specification, and ball roundness is $0.08 \sim 0.09 \mu \mathrm{m}$ which is above grade 5 and close to grade 3 precision bearing ball specification [15].

The current study is focused on the first step of finishing process - lapping. The material removal rate by this eccentric lapping method is very promising, $68 \mu \mathrm{m} /$ hour has been achieved which is 15 times higher than conventional concentric lapping. The aims of current study are to systematically analyse the influences of lapping speed and load on material removal rate, and in particular to explore if the material removal rate can be further increased by using different lubricants and their combinations, and to explore the material removal mechanisms by optical microscope and SEM (Scanning Electron Microscope) investigations.

\section{Experimental Procedure}

\subsection{HIPed Silicon Nitride Ball Blanks}

The test materials used for lapping tests are HIPed (Hot Isostatically Pressed) silicon nitride since this is the most commonly used material in hybrid and all ceramic bearings. The term 'silicon nitride' describes a family of materials which includes alpha- or beta-sialons as well as 'pure' silicon nitride. Silicon nitride materials can contain significant amounts of both crystalline and glassy oxynitride phases whose composition is determined by compounds added to promote densification. More detailed material specification on silicon nitride for precision ball-bearings can be found in references $[13,14]$. Sample balls used for lapping tests were two types of ball blanks purchased directly from the manufacturers. The individual manufacturing processes and characteristics of the two kinds of ball blanks are listed in Table 1.

\subsection{Lapping Machine}

The small-scale eccentric lapping machine used in this investigation is shown in Figure 1. This machine was designed by authors and manufactured in-house. The upper plate is stationary and has a flat lapping surface, and the lower plate which has a circular V-groove on it is driven by a micro- 
inverter controlled AC motor through a belt and pulley system. A summary of lapping test conditions is given in Table 2. A more detailed description of the lapping machine can be found in Reference [15].

\subsection{Test Programme}

Before and after each lapping test run, balls and lapping plates were cleaned using an ultrasonic bath, each ball diameter was measured to $\pm 1 \mu \mathrm{m}$ and the total weight of the batch (15 balls) was measured to $\pm 1 \mathrm{mg}$. Microscope observations of ball surfaces were also conducted after each lapping test run to monitor any exceptional ball surface damage. The diamond paste and lapping fluid were mixed according to paste concentration parameters, and stirred magnetically to mix the diamond paste fully in the lapping fluid. A quantity of $5 \mathrm{ml}$ of this fluid mixture containing diamond particles was spread onto the V-groove of the lower plate before each test. The lapping speed parameter was set by means of choosing the output current frequency of the inverter. Each lapping test was run for 1 hour duration. After each test, each of the 15 balls was measured and the ball diameters were documented. The average weight lost per ball per hour was deduced from the whole batch (15 balls) after each test run purely for monitoring purposes. STDEVP (standard deviation based on the entire population) was also calculated for each test run to monitor the ball diameter scatter.

\section{Results}

\subsection{Under different Lapping Speed}

Fig 2 shows the effect of the rotational speed of the lower lapping plate on material removal rate (designated as average ball diameter reduction per hour and average ball weight lost per hour). Two order 6 polynomial trendlines were added to diameter reduced TP1 data series and diameter reduced TP2 data series respectively. The lapping fluid used was a mixture of $45 \mu \mathrm{m}$ diamond paste and water based lubricant at a ratio $1 \mathrm{~g}: 60 \mathrm{ml}$. The average lapping load was $12.75 \mathrm{~N} / \mathrm{ball}$.

The material removal rate increased as the lapping speed increased. The increase was sharp (higher) from low speed to medium speed $(8.5 \mathrm{rpm}$ to $79 \mathrm{rpm})$ and from medium speed to high speed (140 rpm 169 rpm). The increase was blunt (slower) within the medium speed range (from $79 \mathrm{rpm}$ to 140 rpm). The interesting finding was that although the material removal rates for TP1 and TP2 were very different, they increased proportionately as the speed increased: TP1 was 3 4 fold of TP2 at all 
different lapping speeds except at very low speed. It shows that the material removal rate is strongly dependent on lapping speed. The hardness of TP1 was higher than TP2, so this study illustrated contrary picture to the conventional thinking that the material removal rate would be inversely proportional to the hardness.

Under higher lapping speed (270 rpm and $500 \mathrm{rpm}$ ), the material removal rate can not be increased any further. C-cracks were found on the balls lapped at $270 \mathrm{rpm}$ and surface spalls were found on the balls lapped at the speed of $500 \mathrm{rpm}[16]$.

\subsection{Under different Lapping Load}

Taguchi Methods were used to investigate the influences of different lapping parameters on material removal rate [17]. ANOVA (Analysis of variance) revealed that the lapping load was the most influential parameter. Fig 3 is the level average response analysis result for lapping load parameter. In this investigation, the three levels of lapping load were: $8.82 \mathrm{~N} / \mathrm{ball}, 13.03 \mathrm{~N} / \mathrm{ball}$ and $18.13 \mathrm{~N} / \mathrm{ball}$, which are the typical lapping load in conventional concentric lapping by industry. Due to the algorithm employed in Taguchi Methods for level average response analysis, all the influences from different levels of other parameters (lapping speed, diamond particle size and diamond paste concentration) can be counterbalanced. So, the effect of one parameter (lapping load) on material removal rate can be separated from other parameters. Fig 3 shows, in the range of lapping load from $8.82 \mathrm{~N} / \mathrm{ball}$ to18.13 $\mathrm{N} / \mathrm{ball}$, the material removal rate increased almost linearly with the increase of lapping load at a slope of $(1.5 \mu \mathrm{m} /$ hour $) \times$ lapping load $(\mathrm{N} / \mathrm{ball})$. This information is useful for establishing a theoretical lapping model to show the diamond particles ploughing against ceramic working material using contact mechanics and fracture mechanics.

Under higher lapping load, the material removal rate increased as the lapping load increased, reached the maximum of $68 \mu \mathrm{m} /$ hour at a load of $42.87 \mathrm{~N} / \mathrm{ball}$. At even higher loads, the material removal rate decreased to $55 \mu \mathrm{m} /$ hour at a load of $58.8 \mathrm{~N} / \mathrm{ball}, 25 \mu \mathrm{m} / \mathrm{hour}$ at $77.91 \mathrm{~N} / \mathrm{ball}$ and $20 \mu \mathrm{m} / \mathrm{hour}$ at $106.63 \mathrm{~N} / \mathrm{ball}$ [16]. At the two highest loads (i.e. $7.91 \mathrm{~N} / \mathrm{ball}$ and $106.63 \mathrm{~N} / / \mathrm{ball}$ ), the lapped ball roundness error appeared much bigger, typically $3 \sim 4 \mu \mathrm{m}$, some individual balls even recorded $6 \mu \mathrm{m}$, in sharp contrast to the balls lapped at a load of $58.8 \mathrm{~N} / \mathrm{ball}$ or less which showed a typical roundness error of only $1 \sim 2 \mu \mathrm{m}$. It was assumed that at these extreme high load conditions, the balls being lapped 
were not rolling freely, so the material removal rate decreased and the ball roundness error increased.

This needed to be validated both theoretically and experimentally.

The surface and sub-surface damage effects on balls lapped at the highest load of $106.63 \mathrm{~N} / \mathrm{ball}$ were clearly revealed after polishing and processing in fluorescent dye penetrant. Fig 4 shows typical examples of surface damage. Fig 4 (a) and (b) are the same surface spall under white light and UV (ultra-violet) light respectively. The dimensions of this spall are approximately $170 \mu \mathrm{m} \times 100 \mu \mathrm{m}$ with the maximum depth about $35 \mu \mathrm{m}$ (measured by microscope focus method). The white fluorescent regions shown in Fig 4 (b) indicate sub-surface lateral cracks adjacent to the spall. Fig 4 (c) and (d) show typical surface damage under white light and UV light. Again, there is evidence of sub-surface cracking. These types of damage could be due to the macro-fracture caused by the excessive lapping load. A point or 'star' type feature is shown in Fig 4 (e) and (f). This type of defect is considered to be due to a point overload caused by the over-rolling of a large unbroken diamond particle. Radial cracks are formed similar to those that occur during hardness testing with a diamond indenter. Further lapping removes the dent but the cracks and sub-surface damage are revealed with UV light. No significant surface or sub-surface damage was found on balls lapped at loads $42.87 \mathrm{~N} / \mathrm{ball}$ or less.

\subsection{Under different Lapping Fluids}

During the finishing process of $\mathrm{Si}_{3} \mathrm{~N}_{4}$, tribochemical reactions can play an important part. The fact that water can accelerate the material removal rate on $\mathrm{Si}_{3} \mathrm{~N}_{4}$ has been reported by a number of researchers as reviewed in Section 1. The influence of different lapping fluids and mixtures was one of the major concerns in this study, and has been investigated both at the beginning and at the end of lapping tests.

Six types of lapping fluid and mixture were initially used to investigate their tribochemical reactions with silicon nitride. Table 3 is the summary of these fluid mixtures. The test was on TP2 ball blanks, the lapping speed was $169 \mathrm{rpm}$ and lapping load $12.75 \mathrm{~N} / \mathrm{ball}$. All the mixtures of $45 \mu \mathrm{m}$ diamond paste and lubricant were at a ratio $1 \mathrm{~g}: 60 \mathrm{ml}$. The experimental results are shown in Fig 5 .

The lowest material removal rate was found with type IB fluid, a mixture of $45 \mu \mathrm{m}$ diamond paste and brake fluid. Oil based lubricant (type ID) was better than water based lubricant (type IE). Adding distilled water to the mixture of water based lubricant and $45 \mu \mathrm{m}$ diamond paste (type IA) increased the material removal rate, but the consequence was severe surface pitting. The highest material removal 
rate was found with type IF, a mixture of $45 \mu \mathrm{m}$ diamond paste, water based lubricant, $45 \mu \mathrm{m}$ water based diamond suspension. There was no surface pitting.

After the initial investigation, Taguchi Methods were used to optimise the lapping parameter and the lapping load was found to be most influential [17]. The aggressive lapping test was then conducted, and a maximum material removal rate of $68 \mu \mathrm{m} /$ hour on TP1 was achieved. At this stage, a final investigation was conducted in order to explore the possibility of further increasing the material removal rate by using different lapping fluids and mixtures. All the other parameters were maintained as when the maximum material removal rate of $68 \mu \mathrm{m} /$ hour was achieved, i.e. a lapping load of 42.87 N/ball, and a lapping speed of $169 \mathrm{rpm}$ with a $45 \mu \mathrm{m}$ diamond particle size and a paste concentration of $1 \mathrm{~g}: 30 \mathrm{ml}$. When additional fluid was added to the basic lapping fluid, the additional fluid (distilled water or diamond suspension) was $50 \%$ of the total fluid volume.

Six different combinations of diamond paste and lapping fluid mixtures were used in the final investigation. Table 4 lists all the different combinations. The experimental results are shown in Fig 4. The lowest material removal rate was found by using type FD combination (universal diamond paste and ceramic grinding fluid). This may be due to the fact that this type of fluid is designed for grinding, and is therefore not suitable for lapping. The highest material removal rate was still found using a universal diamond paste and water based lapping fluid (type FC combination). The oil soluble diamond paste with a low viscosity fluid soluble in oil and emulsifiable in water (type FB combination) did not achieve the highest material removal rate. Type FA and type FE combinations were both oil soluble diamond paste with mineral oil based lapping fluid, the only difference was type FE with added distilled water. By adding water, the material removal rate increased from $50 \mu \mathrm{m} / \mathrm{hour}$ to $55 \mu \mathrm{m} / \mathrm{hour}$. Although it has been reported that adding water can significantly increase the material removal rate, as reviewed in Section 1, in this study only a $10 \%$ increase was found. Type FF was a combination of universal diamond paste and water based lapping fluid with added diamond suspension, under which the highest material removal rate was achieved during the initial investigation (denoted as type IF in Table 3 and Fig 5). But in the final investigation on type FF combination, the material removal rate was only $53 \mu \mathrm{m} /$ hour, which is $21 \%$ lower than the highest material removal rate of $68 \mu \mathrm{m} /$ hour.

If the results of the final investigation (Fig. 6) are compared with the results of the initial investigation (Fig. 5), it can be seen that the different lapping fluid mixtures have less effect on material removal rate under a higher lapping load $\quad(42.87 \mathrm{~N} / \mathrm{ball})$ apart from type FD which is not suitable for lapping. 
This may suggest that under a higher lapping load, the predominant material removal mechanism is mechanical, although detailed discussion on the material removal mechanisms will follow in the discussion section. Under a higher lapping load, water based lapping fluid assisted the mechanical removal process of material, thus the highest material removal rate was achieved. This assumption needs to be validated. The ball surfaces lapped by different lapping fluids were examined under a microscope, and no substantial surface damage or extraordinary features were found.

\section{Discussions}

It is only through understanding material removal mechanisms that the nature of the relationship between finishing parameters and surface quality can be revealed. The objective of this study was to investigate the material removal mechanisms experimentally by optical microscope and SEM observations.

As shown by the experimental results described in the previous section and the microscopy and SEM observations on the ball surfaces (Fig 7 and Fig 8), the predominant material removal mechanism during the lapping of ceramic balls in this eccentric lapping machine was still mechanical. This preliminary conclusion is based on the fact that after higher load lapping, no severe chemical reaction feature (for example, surface pitting) was found on the ball surfaces lapped with different fluid mixtures (including added water), and the material removal rate was not increased either. If severe chemical reaction feature were found or the material removal rate were increased considerably, a detailed surface chemical analysis would be necessary. The indentation model on brittle materials developed by Lawn and Wilshaw [18], can be used to assist the explanation of the material removal process. In that model six stages were identified: plastic deformation below the indenter, median vent formation during loading, growth of the median vent into a median crack, closing of the median crack on unloading, lateral cracks appearing under the plastic zone, large lateral cracks leading to chipping.

Fig. 7 show the microscopy and SEM observations on the surfaces of TP1 and TP2 lapped under normal conditions, i. e., lapping load 18.13 N/ball, lapping speed $169 \mathrm{rpm}$ and diamond particle size 45 $\mu \mathrm{m}$. In order to make a comparison between the two kinds of ball blanks, all the observations on the TP1 are in the left column of Fig 7, and all the observations on the TP2 are in the right column. Fig 7 
(a) and (b) are microscopy observations at a magnification of 70×, and Fig 7 (c) and (d) are microscopy observations at a magnification of $700 \times$. These are the typical microscopy appearances for TP1 and TP2 lapped without substantial surface damage throughout the lapping tests.

Fig 7 (b) shows scratch marks on the TP2 surface, which suggest abrasive wear by diamond particles. On the TP1 surface in Fig 7 (a), scratch marks are not obvious. Instead, it features many small, dense and evenly distributed dark areas. Fig 7 (c) shows these small, dense and evenly distributed dark areas under microscopy at high magnification. The dark and bright areas are of approximately equal distribution. In contrast, in Fig 7 (d), which is a TP2 surface under microscopy at the same magnification, the bright area dominates and the dark area is concentrated not uniform. One possible reason for this difference is that although TP1 and TP2 are both made from brittle materials (HIPed $\mathrm{Si}_{3} \mathrm{~N}_{4}$ ), the material property for TP2 is less brittle than that for TP1. The measured surface hardness for a TP2 is 1532 (HV10), being lower than TP1 which is 1682 (HV10). The fracture toughness for TP2 is $6.6 \mathrm{MPa} \mathrm{m}{ }^{1 / 2}$, while for TP1 it is $5.3 \mathrm{MPa} \mathrm{m}^{1 / 2}$. Using the indentation model developed by Lawn and Wilshaw [18] to explain the material removal process, there is a wider plastic deformation zone for the TP2 in the first stage, and in later stages there are fewer median and lateral cracks which lead to chipping due to it being less hard and tougher. The wider plastic deformation zone generated by each diamond particle during lapping leads to wider smoother areas which are the wider bright areas shown in Fig 7 (b) and (d). For the TP1, because it is harder and less tough, there are smaller plastic deformation zones in the first stage, and in later stages there will be more median cracks and lateral cracks leading to chipping. The dark area in Fig 7 (a) and (c) are corresponding to the grain pull-out area in SEM observation in Fig 7 (e) and (g). Although this assumption would be much more convincing if the lapped balls were sectioned to reveal the median and lateral cracks, as an assumption, it is based on the two facts that one is the microscopy and SEM observation in Fig 7, the other is that the material removal rate during lapping for the TP1 is $3 \sim 4$ times higher than for the TP2.

Fig 7 (e) and (g) show the lapped surface of a TP1 under SEM at high magnification $(5000 \times$ and 20000× respectively), and Fig 16 (f) and (h) illustrate the lapped surface of a TP2 under SEM at a magnification of 5000x. The SEM observation suggests that for a TP1, the final material removal (stage six in Lawn and Wilshaw's model: large lateral cracks leading to chipping) features grain pullout, and for TP2, it features bulk material removal by micro-cracks. The SEM observation also suggests that for TP2, the grain size is more uniform and finer than for TP1, although the actual grain 
size and morphology need to be proved by etching techniques. This microstructural difference is directly related to the previous manufacturing processes, i.e. the fabrication of powder and fibre, blending of additives, densification processes, etc. and could have some effect on the material properties thus influencing the material removal process during lapping.

Fig. 8 shows the SEM observation on high load (106.63 N/ball) lapped surfaces of a TP2 ball. The surface cracks can be seen in Fig. 8 (a). Fig.8 (b) shows the detail inside a crack. Under such a high load, steel from the lapping plate was transferred to the ceramic ball surface. This was observed by SEM with EDX and is illustrated in Fig. 9. In Fig 9 (a), the materials in the middle on top of the ball surface were suspected as steel, and in Fig 9 (b) this was confirmed by EDX analysis when focused on these materials. Fig 9 (b) is the element spectrum, the highest element is Fe (steel).

\section{Conclusions}

Two types of HIPed $\mathrm{Si}_{3} \mathrm{~N}_{4}$ bearing ball blanks with different surface hardness and fracture toughness were lapped under various loads, speeds, and lubricants using an eccentric lapping machine to investigate the material removal mechanisms. The experimental results with optical microscope and SEM examination reveal:

1. Lapping load is the most influential factor in relation to material removal rate. The maximum material removal rate was achieved at the lapping load $43 \mathrm{~N} / \mathrm{ball}$. At extreme high lapping load of $78 \mathrm{~N} / \mathrm{ball}$ and $107 \mathrm{~N} / \mathrm{ball}$, the material removal rate decreased and high roundness error, significant surface and subsurface damage were found on the lapped balls.

2. Lapping speed has some influence on material removal rate at the speed raging from $8.5 \mathrm{rpm}$ to 169 rpm. Further increasing the speed to $270 \mathrm{rpm}$ and $500 \mathrm{rpm}$ will not increase the material removal rate.

3. The material removal mechanism during the lapping process of silicon nitride balls is predominately mechanical. Different lapping fluids affected the material removal rate at lower lapping loads, but they had much less influence on the material removal rate at higher lapping loads. The effect of adding water to accelerate the material removal process has not been proved by this study. 
4. The material removal rate on type one (TP1) ball blanks with higher hardness and lower fracture toughness is 3 4 times higher than type two (TP2) ball blanks with lower hardness and higher fracture toughness. The SEM micrographs reveal that the grain pull-out prevailed on the lapped surface of type one ball blanks, and the surface of type two featured bulk material removal by microcracking. This suggests the microstructural difference has played an important part.

\section{References}

[1] S. Chandrasekar and T. N. Farris, Sadhana - Academy Proceedings in Engineering Sciences, 22, (1997), 473-481.

[2] M. Buijs and K. Korpelvanhouten, Journal of Materials Science, 28, (1993), 3014-3020.

[3] M. Buijs and K. Korpelvanhouten, Wear, 166, (1993), 237-245.

[4] Y. Ahn and S. S. Park, Ksme International Journal, 11, (1997), 494-504.

[5] V. H. Bulsara, Y. Ahn, S. Chandrasekar, and T. N. Farris, Journal of Applied MechanicsTransactions of the ASME, 65, (1998), 410-416.

[6] M. N. Gardos and R. G. Hardisty, Tribology Transactions, 36, (1993), 652-660.

[7] J. F. Dill, M. N. Gardos, and R. G. Hardisty, Journal of Engineering For Gas Turbines and Power-Transactions of the Asme, 119, (1997), 196-199.

[8] S. R. Bhagavatula and R. Komanduri, Philosophical Magazine a-Physics of Condensed Matter Structure Defects and Mechanical Properties, 74, (1996), 1003-1017.

[9] M. Woydt and U. Effner, Por. Material Week Symposium 5, edited by A. paoli,, (1996), 153158.

[10] U. Effner and M. Woydt, Wear, 216, (1998), 123-130.

[11] S. R. Hah and T. E. Fischer, Journal of the Electrochemical Society, 145, (1998), 1708-1714.

[12] T. A. Stolarski and E. Jisheng, British Ceramic Transactions, 97, (1998), 61-67.

[13] R. T. Cundill, 4th International Symposium On Ceramic Materials And Components For Engines, (1992), 905-912.

[14] R. T. Cundill, High-precision silicon nitride balls for bearings, 1573., Int Soc for Optical Engineering, Bellingham, WA, USA, 1992, 75-86. 
[15] J. Kang and M. Hadfield, Journal of Engineering Manufacture, Proceedings of Institution of Mechanical Engineer, Part B,, 215, (2001), 781-795.

[16] J. Kang, M. Hadfield, and R. Cundill, "The consequences of aggressive lapping processes on the surface integrity of HIPed silicon nitride bearing balls," Tribology in Environmental Design 2000, Professional Engineering Publishing Limited, London, UK, 227-234.

[17] J. Kang and M. Hadfield, Journal of Engineering Manufacture, Proceedings of Institution of Mechanical Engineer, Part B,, 215, (2001), 69-78.

[18] B. Lawn and R. Wilshaw, J of Mat. Sci., 10, (1975), 1049-1081. 


\section{List of Tables and Figures}

Table 1 Some characteristics of the two types of HIPed silicon nitride ball blanks

Table 2 Summary of lapping materials

Table 3 Different lapping fluids and mixtures used in initial investigation

Table 4 Different lapping fluids and mixtures used in final investigation

Fig. 1 Overview of the novel eccentric lapping machine system

Fig 2 Material removal rate versus lapping speed

Fig 3 Level average response for lapping load parameter in ANOVA by Taguchi Methods

Fig 4 Typical surface and sub-surface damage on ballslapped under a load of $106.63 \mathrm{~N} / \mathrm{ball}$

Fig 5 Initial investigation on material removal rate versus different lapping fluids and mixtures

Fig 6 Final investigation on material removal rate versus different lapping fluids and mixtures

Fig. 7 Microscopy and SEM observation on lapped surfaces, (a), (c), (e), (g) from TP1; (b), (d), (f), (h) from TP2.

Fig. 8 SEM observation on high load lapped surfaces

Fig. 9 SEM with EDX observation on steel transferred to ceramic ball surface 


\begin{tabular}{|l|l|l|}
\hline & $\begin{array}{l}\text { TP1 Ball Blank (from } \\
\text { manufacturer A) }\end{array}$ & $\begin{array}{l}\text { TP2 Ball Blank (from } \\
\text { manufacturer B) }\end{array}$ \\
\hline $\begin{array}{l}\text { Manufacturing } \\
\text { Process }\end{array}$ & Directly HIPed, then rough-ground & Sinter + HIPed \\
\hline Density $\left(\mathrm{kg} / \mathrm{m}^{3}\right)$ & 3160 & 3237 \\
\hline Ball Diameter $(\mathrm{mm})$ & 13.255 & $13.46 \sim 13.50$ \\
\hline $\begin{array}{l}\text { Ball Roundness } \\
\text { Variation }(\mathrm{mm})\end{array}$ & 0.001 & $0.030 \sim 0.075$ \\
\hline $\begin{array}{l}\text { Surface Roughness } \\
\mathrm{R}_{\mathrm{a}}(\mu \mathrm{m})\end{array}$ & 0.202 & 2.645 \\
\hline $\begin{array}{l}\text { Surface Hardness } \\
(\text { Vikers Hardness } \\
\text { Number, VH10) }\end{array}$ & 1682 & 1532 \\
\hline $\begin{array}{l}\text { Fracture Toughness } \\
\text { MPa m }{ }^{1 / 2}\end{array}$ & 5.3 & 6.6 \\
\hline
\end{tabular}

Table 1 Some characteristics of the two types of HIPed silicon nitride ball blanks

Lapping plates

Lapping Fluid material: grey cast iron (grade 12)

upper plate flat

lower plate with eccentric V-groove

$\mathrm{V}$-groove angle $90^{\circ}$ symmetric axis parallel to rotating axis

diameter of circular V-groove $65 \mathrm{~mm}$

eccentricity (distance between centre of circular V-groove and rotating axis)

$8 \mathrm{~mm}$

Kemet diamond compound

Metadi II diamond paste

Diamond particle sizes: $6 \mu, 15 \mu, 30 \mu, 45 \mu, 60 \mu, 90 \mu$

Metadi fluid (water based) 40-6064UK

Table 2 Summary of lapping materials 


\begin{tabular}{|c|c|c|c|}
\hline Type & Diamond Paste & Lubricating Fluid & Other Fluid \\
\hline IA & $\begin{array}{l}45 \mu \mathrm{m} \text { diamond paste } \\
\text { (Buehler Metadi® II 40-6259) }\end{array}$ & $\begin{array}{l}\text { water based lubricant } 50 \% \\
\text { (Buehler Metadi® Fluid } \\
\text { 40-6064) }\end{array}$ & distilled water $50 \%$ \\
\hline IB & $\begin{array}{l}45 \mu \mathrm{m} \text { diamond paste } \\
\left.\text { (Buehler Metadi }{ }^{\circledR} \text { II } 40-6259\right)\end{array}$ & brake fluid & - \\
\hline IC & \multicolumn{2}{|c|}{$\begin{array}{l}45 \mu \mathrm{m} \text { diamond suspension (water based) } \\
\text { (Buehler Metadi® Diamond Suspension 40-6536) }\end{array}$} & - \\
\hline ID & $\begin{array}{l}45 \mu \mathrm{m} \text { diamond paste } \\
\text { (Buehler Metadi® II 40-6259) }\end{array}$ & $\begin{array}{l}\text { oil based lubricant } \\
\text { (Kemet@ Lubricating Fluid } \\
\text { Type OS) }\end{array}$ & - \\
\hline $\mathrm{IE}$ & $\begin{array}{l}45 \mu \mathrm{m} \text { diamond paste } \\
\text { (Buehler Metadi® II 40-6259) }\end{array}$ & $\begin{array}{l}\text { water based lubricant } \\
\text { (Buehler Metadi® Fluid } \\
\text { 40-6064) }\end{array}$ & - \\
\hline IF & $\begin{array}{l}45 \mu \mathrm{m} \text { diamond paste } \\
\text { (Buehler Metadi® II 40-6259) }\end{array}$ & $\begin{array}{l}\text { water based lubricant } 50 \% \\
\text { (Buehler Metadi® Fluid } \\
\text { 40-6064) }\end{array}$ & $\begin{array}{l}\text { Diamond suspension } 50 \% \\
\text { (Buehler Metadi® Diamond } \\
\text { Suspension 40-6536) }\end{array}$ \\
\hline
\end{tabular}

Table 3 Different lapping fluids and mixtures used in initial investigation

\begin{tabular}{|c|c|c|c|}
\hline Type & Diamond Paste & Lubricating Fluid & Other Fluid \\
\hline FA & $\begin{array}{l}\text { Oil Soluble } \\
\text { (Kemet@ 45-L-C1) }\end{array}$ & $\begin{array}{l}\text { Mineral Oil Based } \\
\text { (Kemet® Lubricating Fluid Type OS) }\end{array}$ & - \\
\hline FB & $\begin{array}{l}\text { Oil Soluble } \\
\left.\text { (Kemet }{ }^{\circledR} 45-\mathrm{L}-\mathrm{C} 1\right)\end{array}$ & $\begin{array}{l}\text { Soluble in oil and emulsifiable in } \\
\text { water, containing oil from natural } \\
\text { products } \\
\text { (Kemet@ Lubricating Fluid Type LS) }\end{array}$ & - \\
\hline $\mathrm{FC}$ & $\begin{array}{l}\text { Universal } \\
\text { (Buehler Metadi® } \\
\text { II 40-6259) }\end{array}$ & $\begin{array}{l}\text { Water based } \\
\text { (Buehler Metadi® Fluid } \\
\text { 40-6064) }\end{array}$ & - \\
\hline FD & $\begin{array}{l}\text { Universal } \\
\text { (Buehler Metadi® } \\
\text { II 40-6259) }\end{array}$ & Ceramic grinding fluid & - \\
\hline FE & $\begin{array}{l}\text { Oil Soluble } \\
\text { (Kemet } ® 45-\mathrm{L}-\mathrm{C} 1 \text { ) }\end{array}$ & $\begin{array}{l}\text { Mineral Oil Based } 50 \% \\
\text { (Kemet® Lubricating Fluid Type OS) }\end{array}$ & Distilled water $50 \%$ \\
\hline FF & $\begin{array}{l}\text { Universal } \\
\text { (Buehler Metadi® } \\
\text { II 40-6259) }\end{array}$ & $\begin{array}{l}\text { Water based } 50 \% \\
\text { (Buehler Metadi® Fluid } \\
\text { 40-6064) }\end{array}$ & $\begin{array}{l}\text { Diamond suspension } 50 \% \\
\text { (Buehler Metadi® Diamond } \\
\text { Suspension 40-6536) }\end{array}$ \\
\hline
\end{tabular}

Table 4 Different lapping fluids and mixtures used in final investigation 


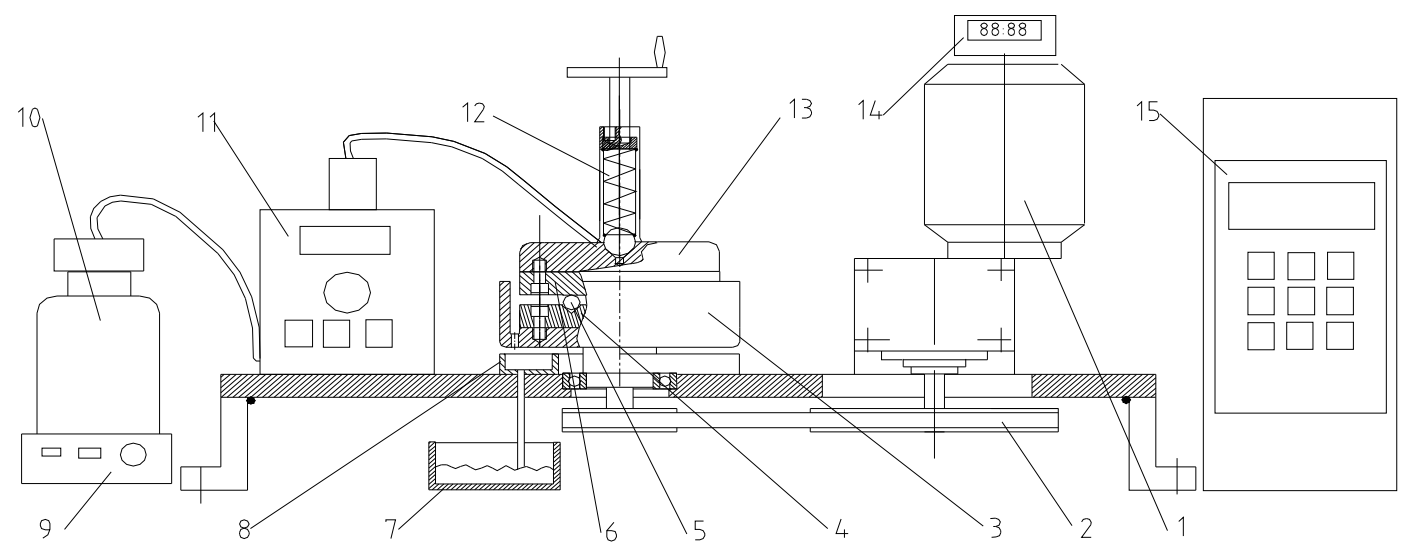

1 AC motor and gearbox combination 2 Pulleys and belt 3 Flange shaft 4 Lower plate 5 Ceramic ball 6 Upper plate 7 Lapping fluid collection tank 8 Lapping fluid tray 9 Magnetic stirrer 10 Lapping fluid container 11 Pump 12 Spring-loading Unit 13 Backing plate 14 Time counter 15 MicroMaster inverter

Fig. 1 Overview of the novel eccentric lapping machine system 


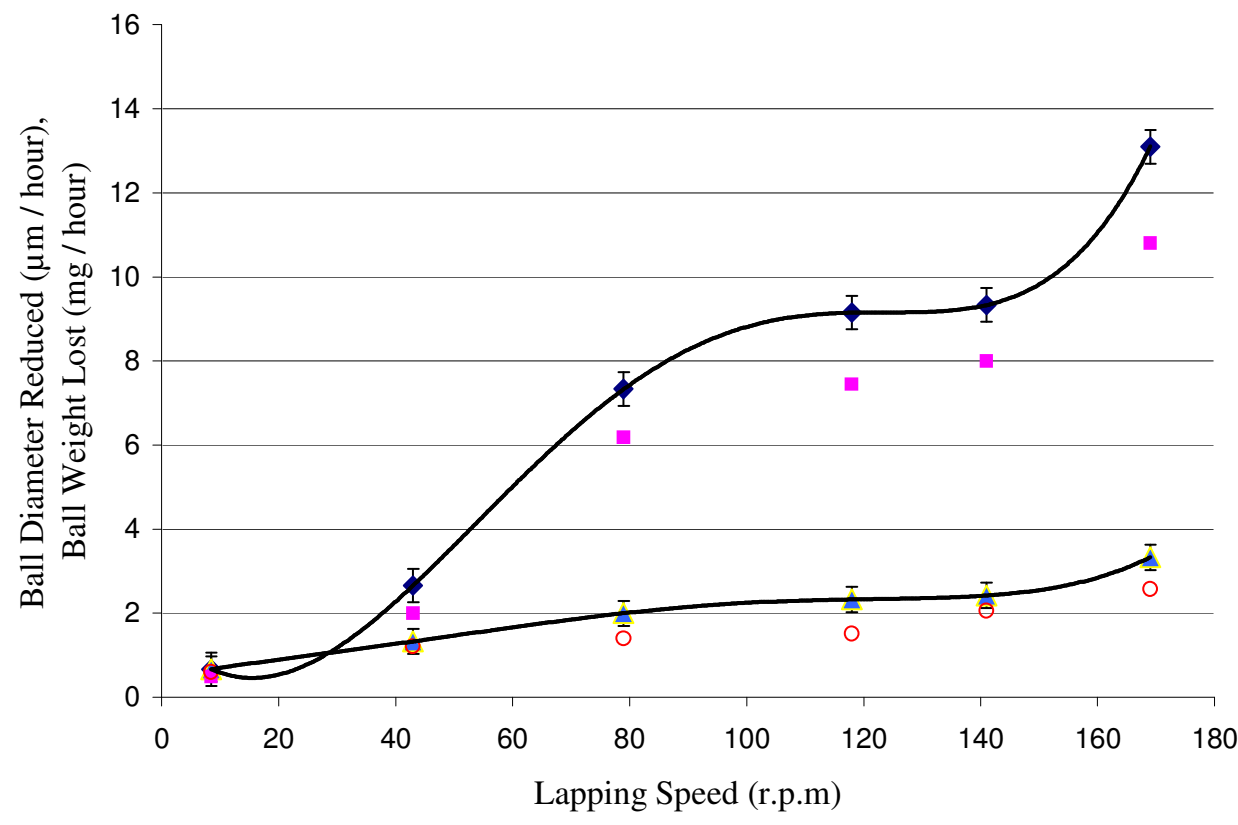

- Diameter Reduced TP1

- Weight Lost TP1

A Diameter Reduced TP2

○ Weight Lost TP2

— Poly. (Diameter Reduced TP1 ) —Poly. (Diameter Reduced TP2)

Fig 2 Material removal rate versus lapping speed 


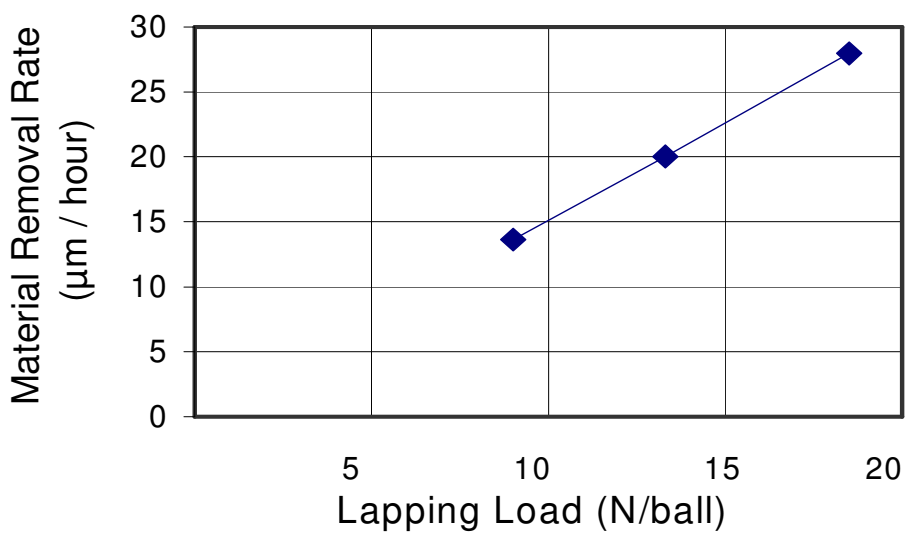

Fig 3 Level average response for lapping load parameter in ANOVA by Taguchi Methods 


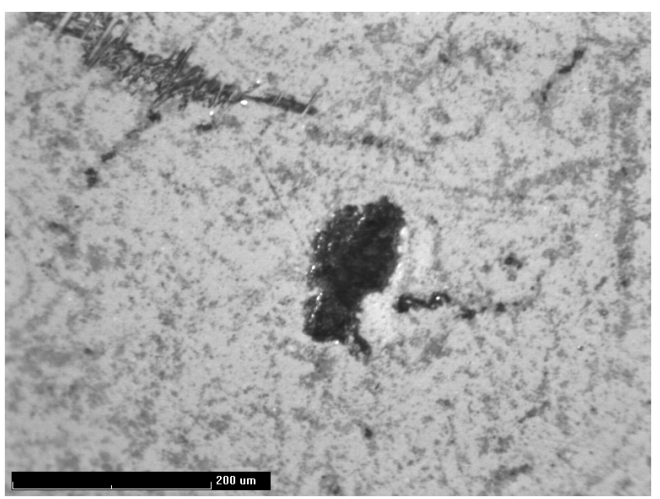

(a) Surface spall under white light

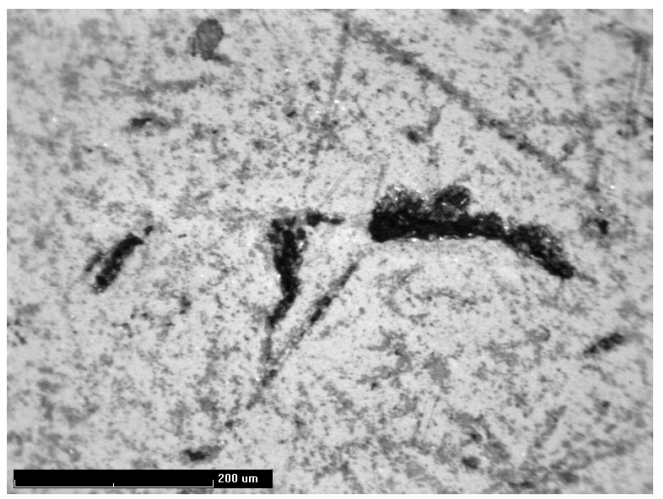

(c) Surface crack under white light

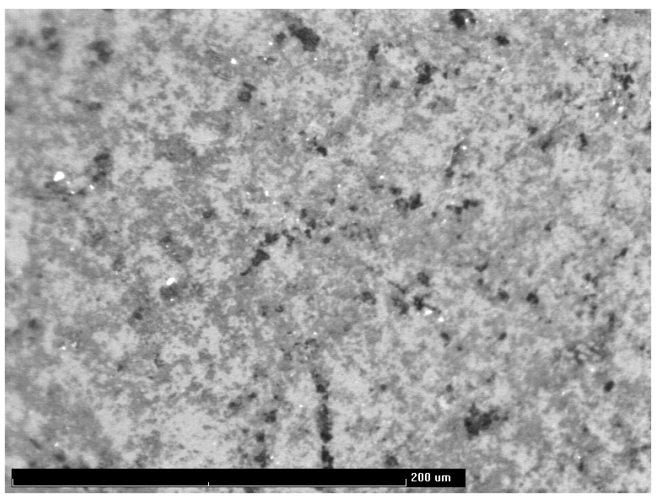

(e) Sub-surface crack under white light

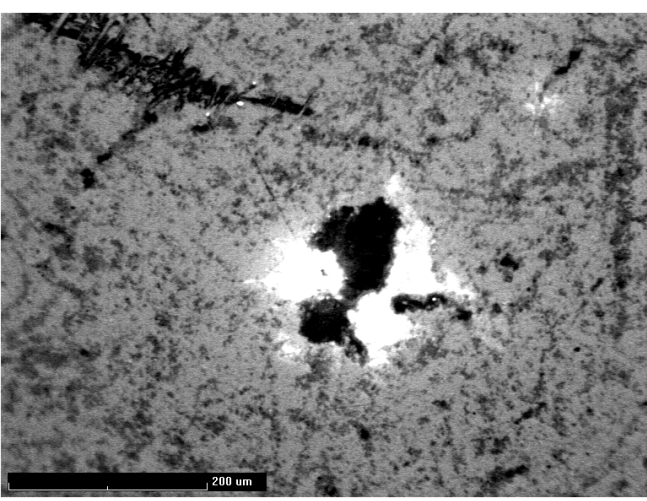

(b) Surface spall under UV light

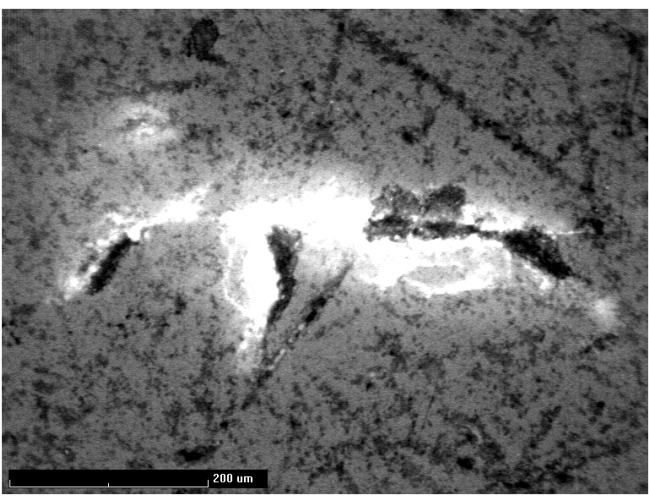

(d) Surface crack under UV light

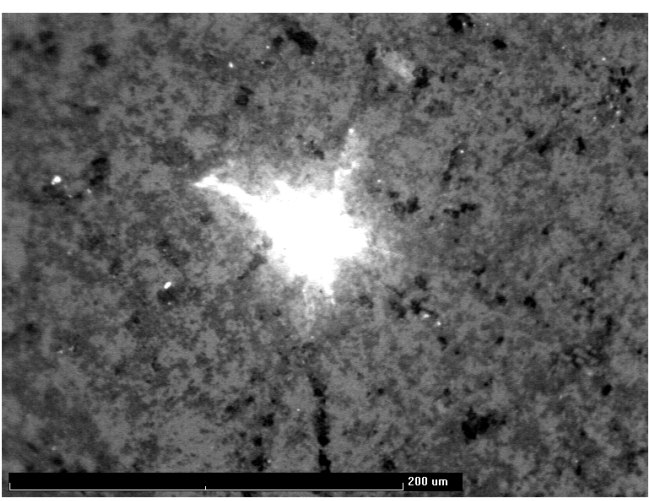

(f) Sub-surface crack under UV light

Fig 4 Typical surface and sub-surface damage on balls

lapped under a load of $106.63 \mathrm{~N} / \mathrm{ball}$ 


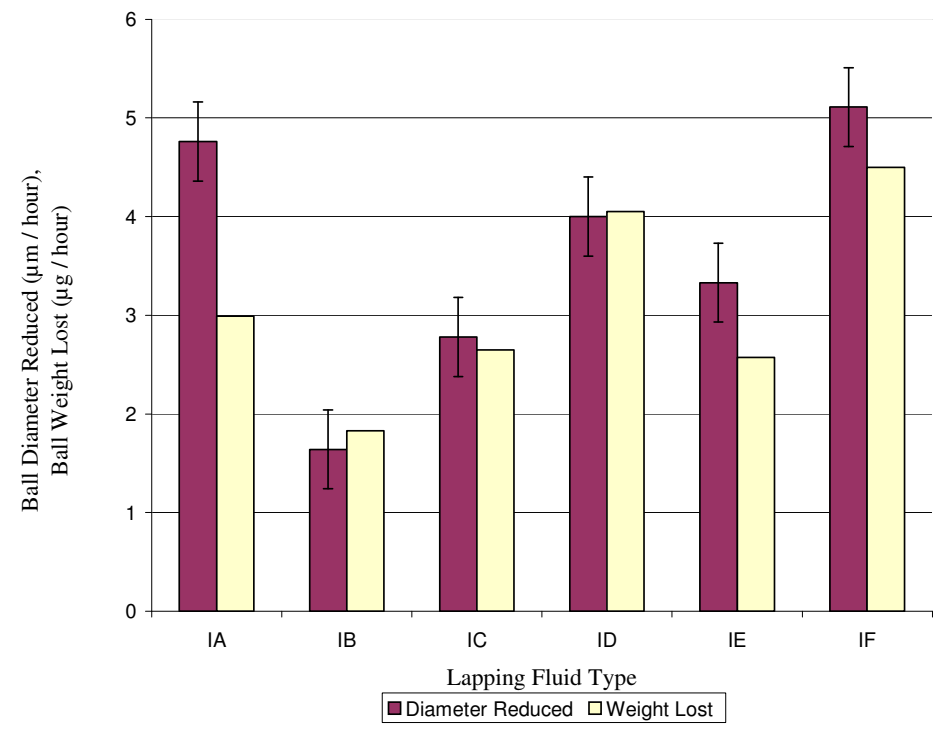

Fig 5 Initial investigation on material removal rate versus different lapping fluids and mixtures

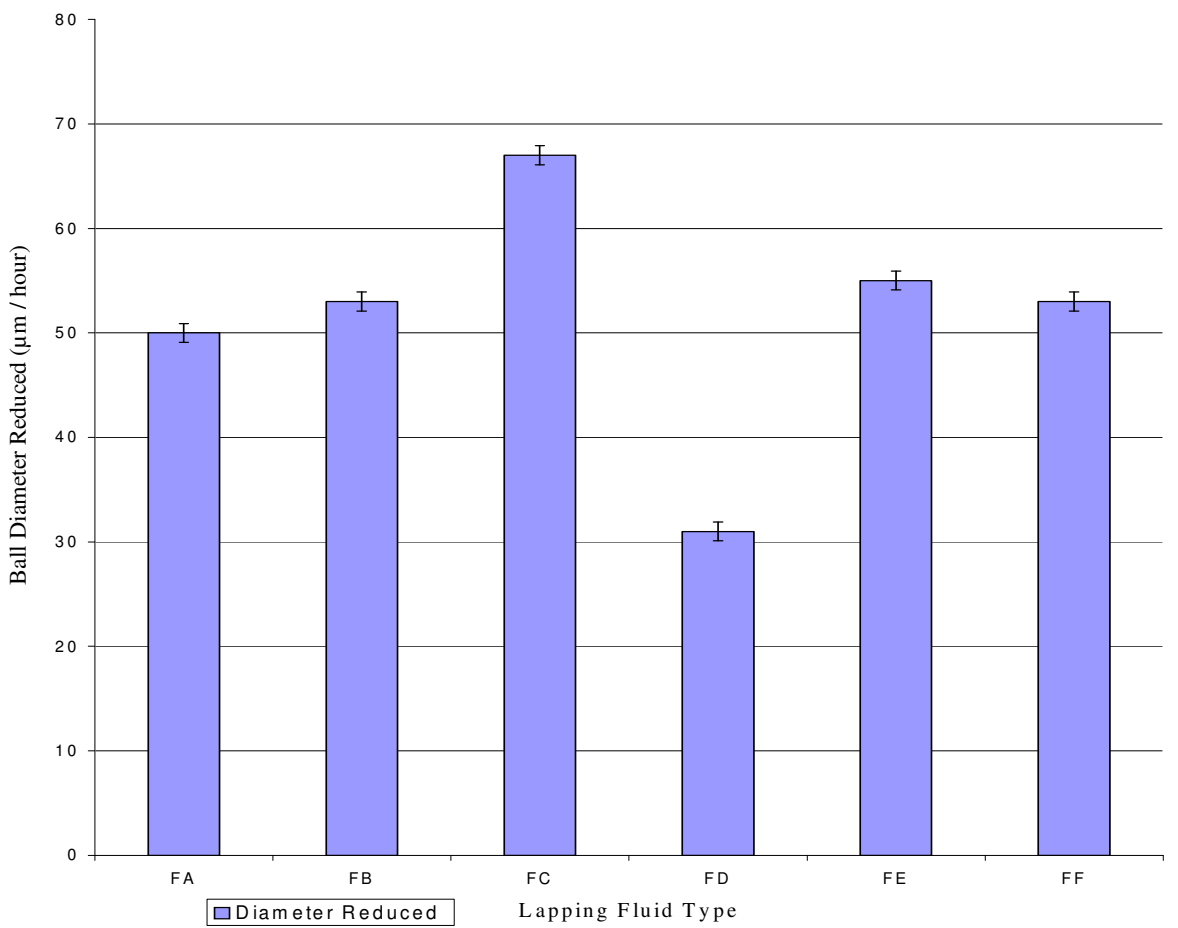

Fig 6 Final investigation on material removal rate versus different lapping fluids and mixtures 


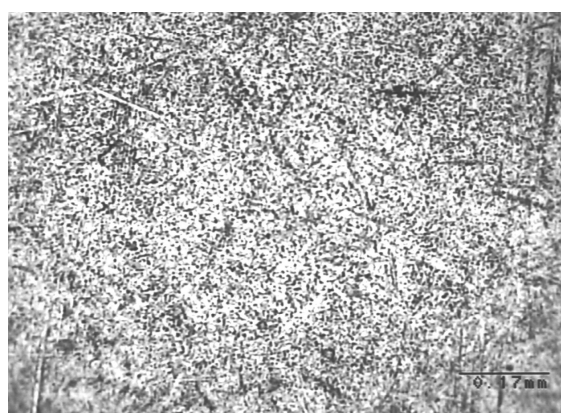

(a) TP1 microscope $70 \times$

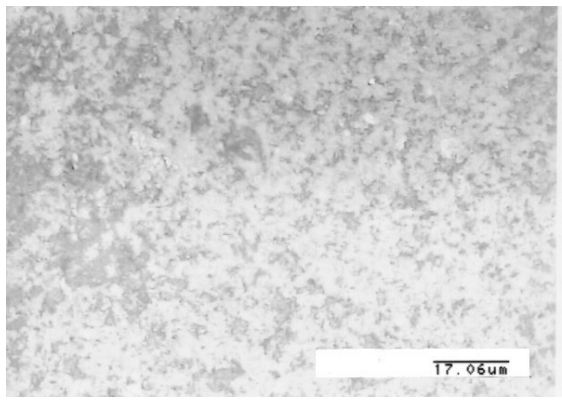

(c) TP1 microscope $700 x$

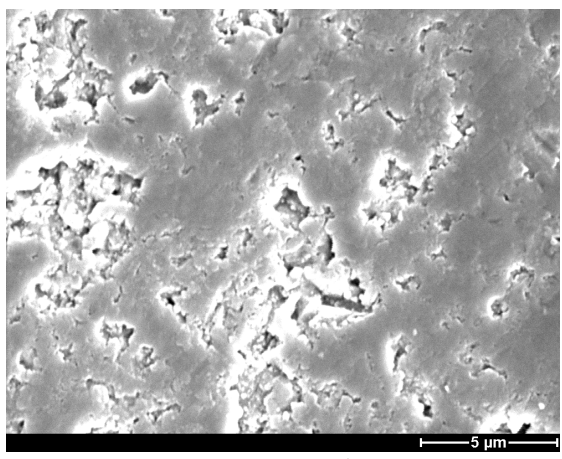

(e) TP1 SEM 5000 $\times$

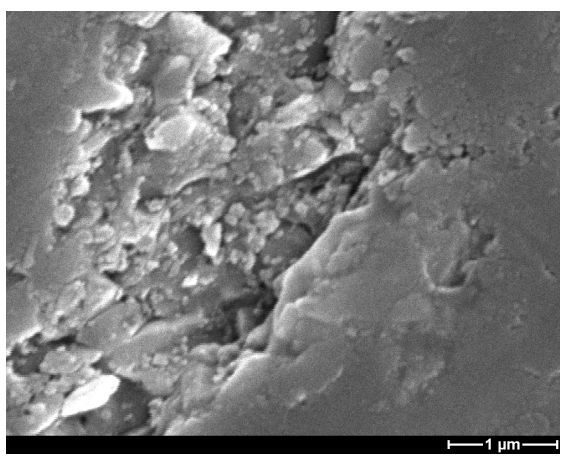

(g) TP1 SEM 20000x

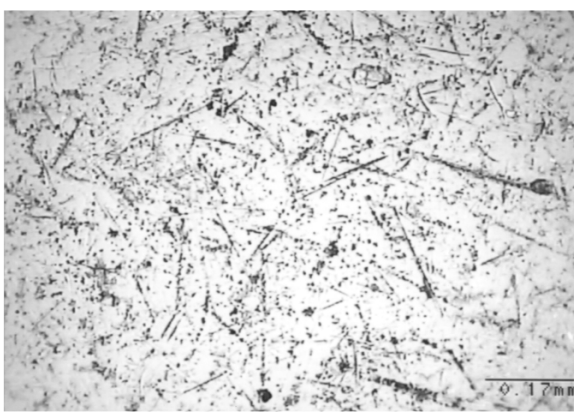

(b) TP2 microscope $70 x$

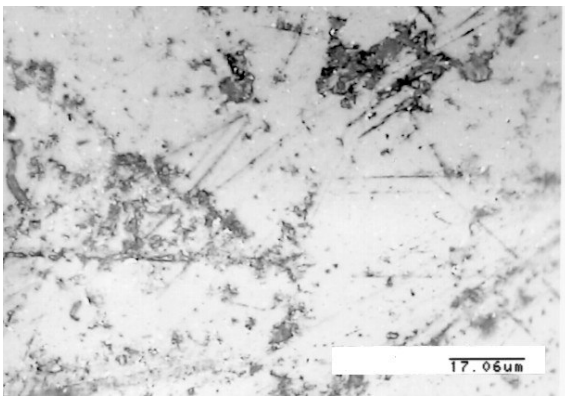

(d) TP2 microscope $700 x$

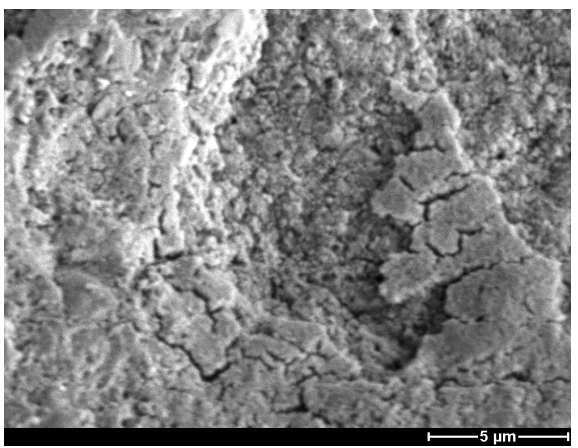

(f) TP2 SEM 5000x

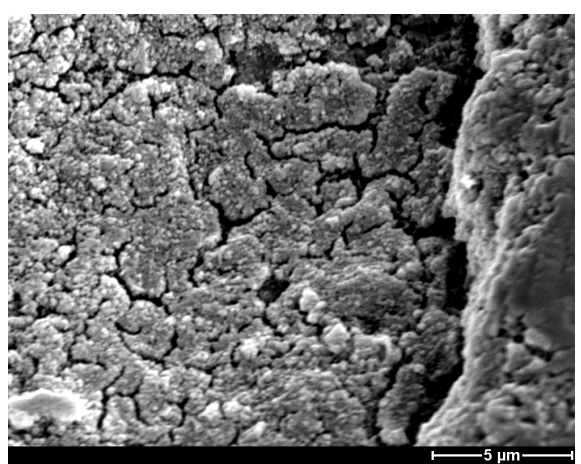

(h) TP2 SEM 5000x

Fig. 7 Microscopy and SEM observation on lapped surfaces, (a), (c), (e), (g) from TP1; (b), (d), (f), (h) from TP2 


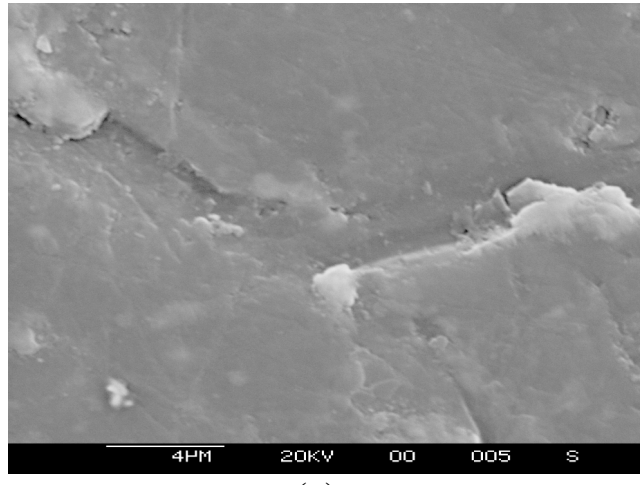

(a)

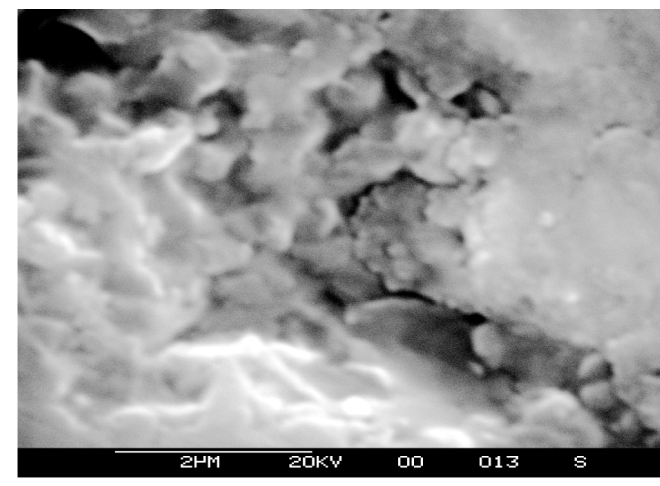

(b)

Fig. 8 SEM observation on high load lapped surfaces

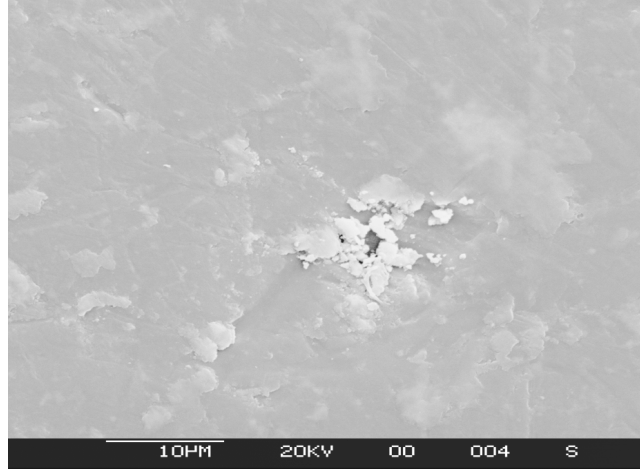

(a)

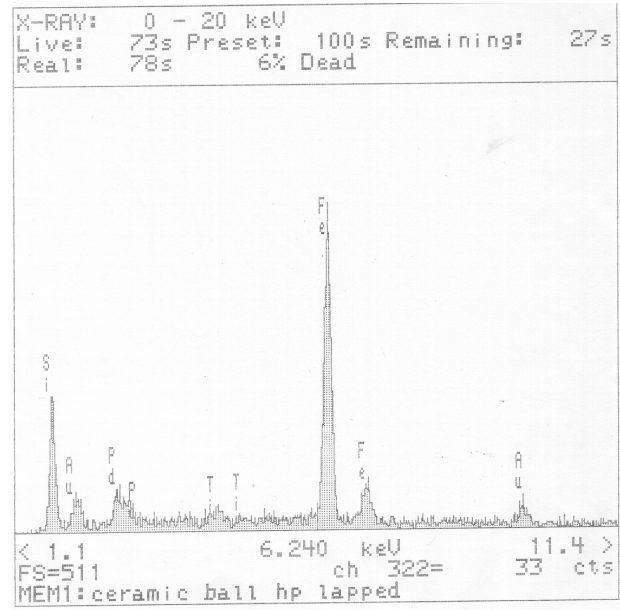

(b)

Fig. 9 SEM with EDX observation on steel transferred to ceramic ball surface 